2. Edmunds W. Cystic adenoma of the kidney. Trans Pathol Soc London. 1892;43:89-90.

3. Powell T, Shackman R, Johnson HD. Multilocular cysts of the kidney. Br J Urol. 1951;23:142-52.

4. Boggs LK, Kimmelstiel P. Benign multilocular cystic nephroma: Report of two cases of so-called multilocular cyst of the kidney. J Urol. 1956;76:530-41.

5. Joshi VV, Beckwith JB. Multilocular cyst of the kidney (cystic nephroma) and cystic partially differentiated nephroblastoma: Terminology and criteria for diagnosis. Cancer. 1989;64:466-79.

6. Bruce Droecker MD. Non-Wilms'renal tumours in children. Urol Clin North Am. 2000;27.

7. Castillo OA, Boyle ET, Kramer SA. Multilocular cysts of kidney: A study of 29 patients and review of literature. Urology. 1991;37:156-62.

8. Aguilar Ruiz A, Torramilans Lluis A, Castells Esteve M, Vargas Blasco C. Nefroma multilocular quístico. Presentación de un caso. Act Urol Esp. 2003;27:718-20.
9. Morga JP, Fontana LO, Martínez F, García F, Sempere Gutiérrez A, Rico Galiano JL, et al. Nefroma quístico multiloculado. Un reto diagnóstico y terapéutico, a propósito de dos casos. Arch Esp Urol. 2004;57:431-4.

10. López Aramburo MA, Claver Criado M, Gutiérrez Minguez E, Arroyo Muñoz JL, Espiga Santamaria FJ, Gómez López A, et al. Quiste multilocular renal: consideraciones clínico-patológicas. Act Urol Esp. 1989;13:1.

\section{M.P. Bahílo Mateu*, A. Budía Alba, F. Boronat Tormo y} F.J. Jiménez-Cruz

Servicio de Urología, Hospital Universitario La Fe, Valencia, España

*Autor para correspondencia.

Correo electrónico: pilarbahilo@hotmail.com

(M.P. Bahílo Mateu).

\title{
Metástasis al cuero cabelludo de carcinoma de células claras
}

\section{Metastasis to scalp of clear cell carcinoma}

\section{Sr. Director:}

El carcinoma de células renales (CCR) es uno de los tumores urológicos más agresivos, representando cerca del 3\% de las neoplasias del adulto. Este tumor está caracterizado por una evolución clínica imprevisible. Aproximadamente un tercio de los pacientes con CCR tienen enfermedad metastásica en el momento de la presentación inicial.

Las metástasis cutáneas representan una diseminación importante de la enfermedad, generalmente en casos muy avanzados, y se asocia un pronóstico muy desfavorable.

Presentamos el caso de un paciente masculino de 51 años que consultó al dermatólogo con 3 meses de evolución de notar nódulos en el cuero cabelludo que aumentaban de tamaño, indoloros, pruriginosos, de fácil sangrado al contacto (fig. 1).

Negaba pérdida de peso, hematuria macroscópica y/o dolor.

Se tomó una biopsia de los nódulos, la cual reportó metástasis al cuero cabelludo de carcinoma de células claras (fig. 2).

Se solicitó evaluación del paciente por el Servicio de Urología; se indicó una tomografía computarizada.

Al paciente se le realizó una nefrectomía radical izquierda. Cinco meses luego de la cirugía el paciente presentó una fractura patológica del fémur izquierdo, se indicó una gammagrafía ósea, observando múltiples metástasis; en la radiografía de tórax se observaban metástasis pulmonares.
El paciente no asistió a los controles con el Servicio de Urología, y falleció 9 meses luego de la nefrectomía.

El CCR convencional o de células claras constituye alrededor de un 70-80\% de todos los carcinomas de células renales y representa la variedad más frecuente ${ }^{1}$.

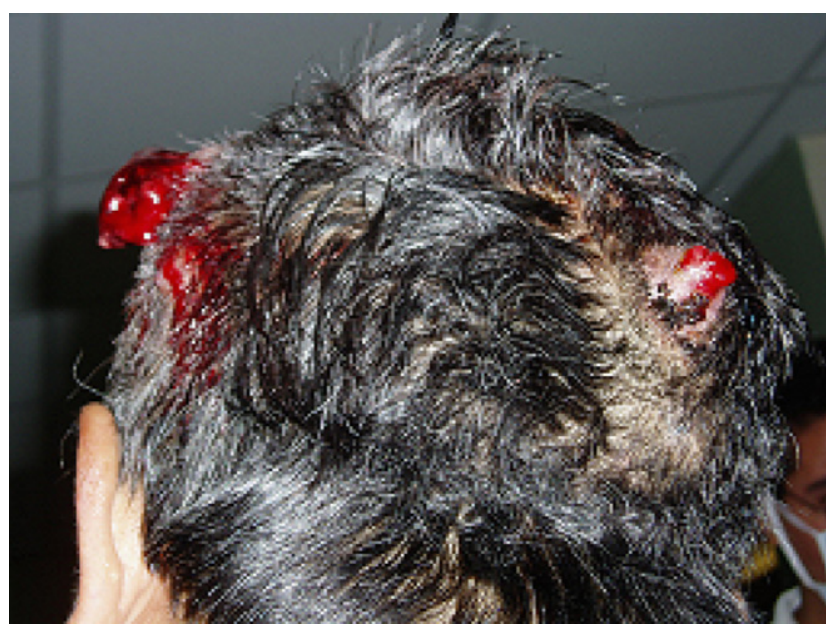

Figura 1 - Aspecto de las lesiones cutáneas en el cuero cabelludo. Obsérvense los nódulos bien delimitados. 


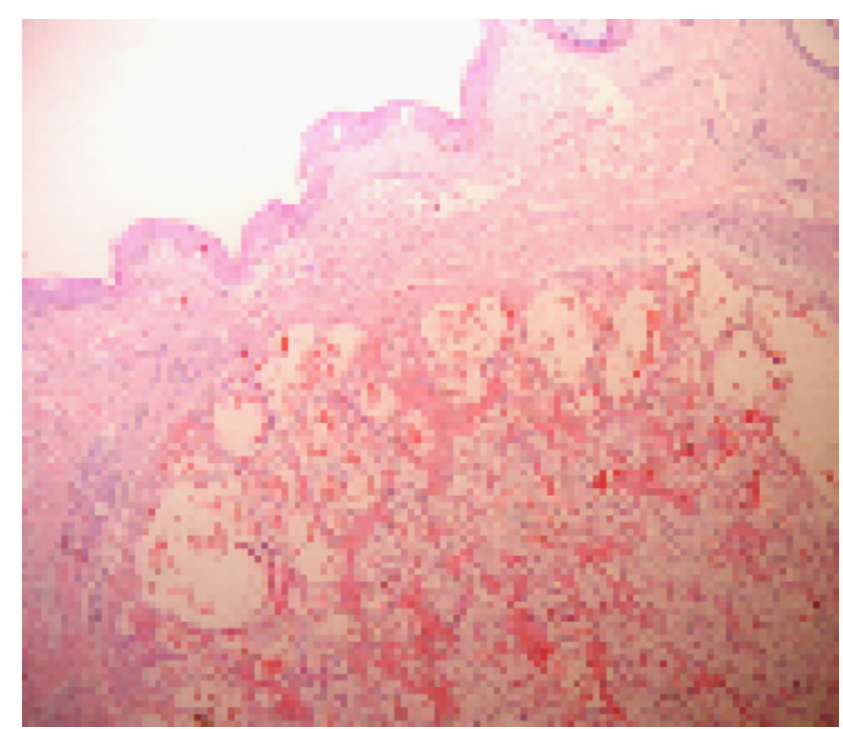

Figura 2 - Biopsia del cuero cabelludo (H-E $10 \times$ ): invasión a la dermis por neoplasia compuesta por células claras.

La tríada clásica de dolor lumbar, hematuria macroscópica y masa abdominal palpable es un hallazgo raro en la actualidad, ocurre apenas en el 5-15\% de los casos, correlacionándose con enfermedad avanzada, siendo actualmente designada como «tríada demasiado tarde» ${ }^{1}$.

Aproximadamente un tercio de los pacientes con CCR tienen enfermedad metastásica en el momento de la presentación inicial, las más frecuentes en el pulmón y el hueso ${ }^{2}$. La metástasis a la piel del CCR es infrecuente, con una incidencia aproximada entre un 2,4-6,4\% ${ }^{2}$.

Las metástasis son más frecuentes en los hombres ${ }^{3,4}$.

En una serie estudiada de 724 pacientes con metástasis cutáneas en 1972 se determinó que en mujeres el primario correspondía a mama en un $69 \%$, a intestino grueso en un $9 \%$ y a pulmón, ovario y melanoma maligno en un 4-5\%. En el sexo masculino, el $24 \%$ de los carcinomas metastáticos a la piel tuvo su origen en los pulmones, el 19\% en el intestino grueso, el $13 \%$ en el melanoma maligno, el $12 \%$ en la cavidad oral, el $6 \%$ en el riñón y $6 \%$ en el estómago ${ }^{5,6}$.

En la mayoría de los pacientes las metástasis cutáneas del CCR aparecen en un estadio tardío de la enfermedad, y en ocasiones pueden aparecer con antelación al diagnóstico del tumor renal ${ }^{8,9}$. En general, se consideran una manifestación tardía de la enfermedad, de mal pronóstico, y con una supervivencia media después de la detección de la metástasis cutánea de 7 meses $3,7,9$.

El aspecto clínico de las metástasis de CCR a la piel puede simular otros trastornos dermatológicos comunes que afectan a pacientes con tumores malignos avanzados ${ }^{7}$.

La localización de las metástasis cutáneas tiene lugar fundamentalmente a nivel de la cabeza, el tórax y el abdomen, en este orden ${ }^{3}$. Suelen ser lesiones únicas que varían de unos milímetros a unos centímetros de diámetro, de crecimiento rápido en forma de nódulos subcutáneos bien delimitados o placas infiltrantes, las cuales pueden ser tanto dolorosas como indoloras, también se pueden describir como una masa pulsátil y van desde el color carne hasta el violáceo ${ }^{2}$.

Cabe destacar que cuando un paciente debuta con metástasis cutánea de CCR, la historia clínica y el examen físico pueden no orientar a un diagnóstico certero, por lo tanto, el diagnóstico histopatológico es fundamental; además, las metástasis cutáneas del CCR son sin duda un signo de mal pronóstico.

B I B L I O G R A F Í A

1. Walsh P, Retik A, Vaughan E, Wein A. Campbell Urología. Editorial Médica Panamericana. 2004;4:2935-8.

2. Gay HA, Cavalieri R, Allison RR, Finley J, Quan Jr WD. Complete response in a cutaneous facial metastatic nodule from renal cell carcinoma after hypofractionated radiotherapy. Dermatol Online J. 2007;13:6.

3. Dorairajan LN, Hemal AK, Aron M, Rajeev TP, Nair M, Seth A, et al. Cutaneous metastases in renal cell carcinoma. Urol Int. 1999;63:164-7.

4. Páez Borda A, Nacarino Corbacho L, Diego García A, Prieto Chaparro L, Delgado Martín JA, Salinas Casado J, et al. Metástasis cutáneas y ginecológicas reveladoras del carcinoma de células renales: Implicaciones diagnósticas y terapéuticas. Arch Esp Urol. 1992;45:341-5.

5. Walter LF. Metastatic carcinoma and carcinoid. Histopathology of the skin. EE. UU.: Lippincott Company; 1990:651-59.29.

6. Lookingbill DP, Spangler N, Helm KF. Cutaneous metastases in patients with metastatic carcinoma: A retrospective study of 4020 patients. J Am Acad Dermatol. 1993;29:228-36.

7. Mueller T, Wu H, Greenberg R, Hudes G, Topham N, Lessin S, et al. Cutaneous metastases from genitourinary malignancies. Urology. 2004;63:1021-6.

8. Kouroupakis D, Patsea E, Sofras F, Apostolikas N. Renal cell carcinoma metastases to the skin: A not so rare case? Br J Urol. 1995;75:583-5.

9. Koga S, Tsuda S, Nishikido M, Matsuya F, Saito Y, Kanetake H. Renal cell carcinoma metastatic to the skin. Anticancer Res. 2000;20:1939-40.

G. Navarrete-Gutiérrez ${ }^{\mathrm{a}, *}$, A. Fuentes-Valencia ${ }^{\mathrm{a}}$, J. SalaverríaCáceres $^{\mathrm{a}}$ y G. Vela-Jiménez ${ }^{\mathrm{b}}$

${ }^{a}$ Servicio de Urología, Hospital General ISSS, San Salvador, El Salvador, C.A.

${ }^{\mathrm{b}}$ Departamento de Patología, Hospital General ISSS, San Salvador, El Salvador, C.A.

*Autor para correspondencia.

Correo electrónico: dr.gnavarrete@hotmail.com

(G. Navarrete-Gutiérrez). 